\title{
Characterization of aerosol types over Lake Urmia Basin
}

\author{
Sanaz Moghim ${ }^{1, *}$, and Reyhaneh Ramezanpoor ${ }^{1}$ \\ ${ }^{1}$ Water and Environment, Civil Eng. Dep., Sharif University of Technology, 11155-4313 Tehran, Iran
}

\begin{abstract}
Atmospheric aerosols affect the Earth's climate, air quality, and thus human health. This study used the Aerosol Optical Depth (AOD) and the Ångström exponent to cluster different particle types over the Lake Urmia Basin. This classification found desert dust and marine (mixed with continental or local-pollution aerosols) as two main aerosol types over the region, while their sources are not well defined. Although different air masses and wind circulation over the study domain in varied months can help to distinguish aerosol sources, measurements are crucial for a complete evaluation.
\end{abstract}

\section{Introduction}

Iran like most countries is affected by different forcing such as human activities and climate change. These forcings can cause environmental degradation and also ecosystem and resources (e.g., land, water, air) destruction. Anthropogenic activities and improper management caused a dramatic shrinking of the Aral Sea in Central Asia, which was once the fourth largest lake in the world. Drying Aral Sea had serious impacts on human health and ecological balance [1]. Similarly, Lake Urmia in Iran, which was once the largest lake in the Middle East, has been drying. Drying of the lake causes dust storms.

Remote sensing is able to provide indicators and measures to assess aerosol. One of the most common indicators is Aerosol Optical Depth (AOD). Mahowald et al. (2003) used AOD to evaluate desert dust sources in Algeria and Namibia. They also studied the role of the lakes in modifying mineral aerosols [2]. Di et al. (2016) used Indian National Satellite (INSAT) data to derive AOD. Their results showed that retrieved AOD can detect dust storms in Xinjiang region in China [3]. Hsu et al. (2004) retrieved aerosol properties over three areas (arid, semiarid, and urban) using surface reflectance from remote sensing data in visible and NIR (near infrared) wavelengths [4]. Their algorithm called Deep Blue includes lookup tables that can simulate spectral radiances. Results show that Deep Blue algorithm can determine the aerosol optical thickness and aerosol type. The Ångström exponent can be used to discriminate between dust plumes and fine particles of pollution [5]. Ginoux et al. (2012) used the Deep Blue MODIS aerosol product to categorize the natural and anthropogenic dust sources around the world [6]. They showed that about three-quarters of the dust origins are natural and one-quarter is related to the anthropogenic dust. Their results can also distinguish anthropogenic dust at different regions such as the border of Iran, Iraq, and Saudi Arabia. Toledano et al. (2007) used a five-year aerosol database from INTA-El Arenosillo (Huelva, Spain) to classify aerosol properties [7]. They determined four aerosol types based on different ranges of AOD and Ångström exponent. Their results showed that coastal marine aerosols and desert dust are two main aerosol types at El Arenosillo. Prasad and Singh (2007) used AOD and Ångström exponent to track dust storms in the IndoGangetic (IG) plain. Their results warned people in the region about health risks associated with the dust storms [8]. Since the particle type determines the impacts on ecosystem functioning and human health, proper tools and measures are required to identify and distinguish them.

\section{Study domain}

This study aims to evaluate changes in aerosol types particularly dust over the Lake Urmia basin, which is located in Northwest of Iran (with the coordinate of Lat: $37^{\circ} 42^{\prime} \mathrm{N}$ and Lon: $45^{\circ} 19^{\prime} \mathrm{E}$, see Fig. 1). The lake was the second largest saline lake in the world and the home of different species. Lake Urmia has been drying fast, which provided conditions for dust and sand storm formation.

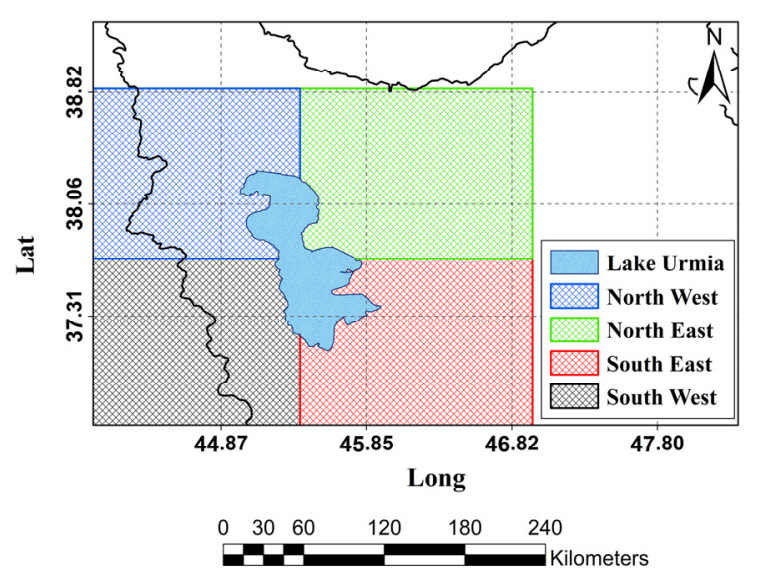

Figure 1. The study domain including Lake Urmia and four subregions (Northwest, Southwest, Northeast, and Southeast).

* Corresponding author: moghim@sharif.edu 


\section{Dataset}

This study uses Visible Infrared Imaging Radiometer Suite (VIIRS) product to obtain Aerosol Optical Depth (AOD) at 11 wavelengths. VIIRS (on-board the National Polar-orbiting Partnership satellite), following on from NOAA AVHRR and Terra/Aqua MODIS missions, provides imaging and remote sensing datasets over a broad wavelength range from 0.41 to $12.5 \mu \mathrm{m}$. VIIRS data can be used for more than twenty environmental applications including aerosol and cloud properties measurements. The data are global in daily resolution, available at https://jointmission.gsfc. nasa.gov/viirs.html.

\section{Methodology}

Many studies have used AOD to indicate dust events. A related question is whether this indicator can evaluate different sources and types of aerosol completely. To address this question, first we analyze AOD changes of different wavelengths to check if there is a specific range of wavelength that can distinguish different particle types. To investigate different types and sources of aerosols over the Lake Urmia basin, the region is divided into four subregions (Fig. 1) including Northwest (NW), Southwest (SW), Northeast (NE), and Southeast (SE). The monthly variation of the AOD at different wavelengths in year 2016 over the entire study domain is illustrated in Fig. 2. Results demonstrate that the annual cycle of the AOD at different wavelengths has almost similar pattern with larger ranges in smaller wavelengths (e.g. $412 \mathrm{~nm}$ and $550 \mathrm{~nm}$ ). Note that due to similar behaviour of the AOD at other wavelengths, results are shown just for wavelengths including 412, 550, 1240, and $2250 \mathrm{~nm}$.

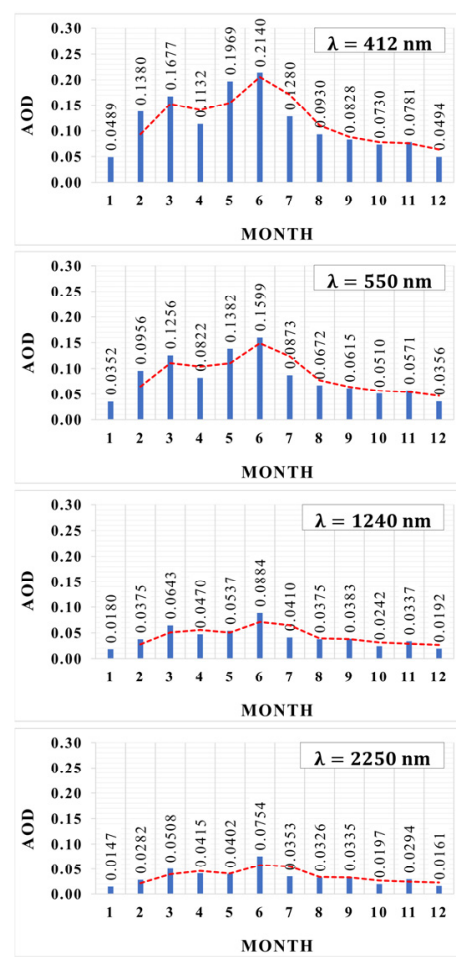

Figure 2. Monthly variation of the AOD at four wavelengths.
Figure 2 confirms that AOD at $412 \mathrm{~nm}$ and $550 \mathrm{~nm}$, which are mostly used to detect dust, show stronger annual cycles. Although AOD can present aerosol loading, it cannot distinguish different types of aerosols. Indeed, varied aerosols' sources can be distinguished by the spectral dependency of different aerosol types (presented by Ångström exponent $\alpha$ ). Thus, to extract maximum possible information from AOD, we derive Ångström exponent using AOD of the VIIRS product at two wavelengths as $\alpha=-\log \left(\frac{\operatorname{AOD}_{\lambda_{1}}}{\operatorname{AOD}_{\lambda_{2}}}\right) / \log \left(\frac{\lambda_{1}}{\lambda_{2}}\right)$, where $\lambda_{1}=440 \mathrm{~nm}$ and $\lambda_{2}=870 \mathrm{~nm}$. The Ångström exponent that is inversely related to the particle size and indicates the AOD's dependency on the wavelength. Larger particles have smaller $\alpha$ and vice versa. Indeed, AOD can track existence of the aerosol and $\alpha$ can provide information about the size of the aerosol. Thus, the combination of the AOD and $\alpha$ can provide more valuable information for aerosol classification. This work uses AOD and $\alpha$ to characterize aerosol properties. The thresholds for AOD and $\alpha$ in aerosol classification are determined by Toledano et al. for their observations [7]. Their classification divides aerosol types into four classes including marine, continental, biomass-burning, and desert dust. Marin type includes marine and urbanpolluted aerosols. We use their classification to cluster different types of particles over the Lake Urmia basin as Tab. 1 [7].

Table 1. Aerosol classification [7]. $\mathrm{AOD}_{1}$ is at $\lambda=870 \mathrm{~nm}$ and $\mathrm{AOD}_{2}$ is at $\lambda=440 \mathrm{~nm}$.

\begin{tabular}{|l|c|c|c|}
\hline & $\mathrm{AOD}_{1}$ & $\mathrm{AOD}_{2}$ & $\alpha$ \\
\hline Marine & - & $<0.2$ & $0-2$ \\
\hline Continental & - & $0.2-0.35$ & $>1.05$ \\
\hline $\begin{array}{l}\text { Biomass- } \\
\text { burning }\end{array}$ & - & $>0.35$ & $>1.4$ \\
\hline Desert dust & $>0.11$ & - & $<1.05$ \\
\hline
\end{tabular}

Toledano et al. (2007) showed that small $\alpha$ and large AOD in longer wavelengths (e.g. $870 \mathrm{~nm}$ ) can identify desert aerosol. On the other hand, short wavelengths (e.g. $440 \mathrm{~nm}$ ) can better determine continental, marine, and biomass-burning aerosols [7]. Thus, they used $\mathrm{AOD}_{1}$ (at $\lambda=870 \mathrm{~nm})$ and $\alpha$ as dominant direct indicators for desert dust and $\mathrm{AOD}_{2}$ (at $\lambda=440 \mathrm{~nm}$ ) and $\alpha$ as direct indicators for other groups (marine, continental, and biomass-burning). The chance of overlapping two groups of this classification including marine and dust types is also checked for this case study. We found that there is just less than $5 \%$ of the pixels that are sparsely located and considered in both groups. For these limited pixels, we used the neighbouring pixels (marine or dust) to define their groups. Although these thresholds can cause errors and decrease the accuracy of this clustering, Lake Urmia basin like many other regions does not have observations to increase the validity of the method. Thus we believe this classification can help to track changes in aerosol types particularly dust over the basin. 


\section{Results}

To analyze aerosol properties, AOD and $\alpha$ are used to cluster different types of particles in March and June 2016 (Figs. 3 and 4, respectively). To better evaluate aerosol sources, the wind velocity is also illustrated over the domain in Figs. 3 and 4.

(a)

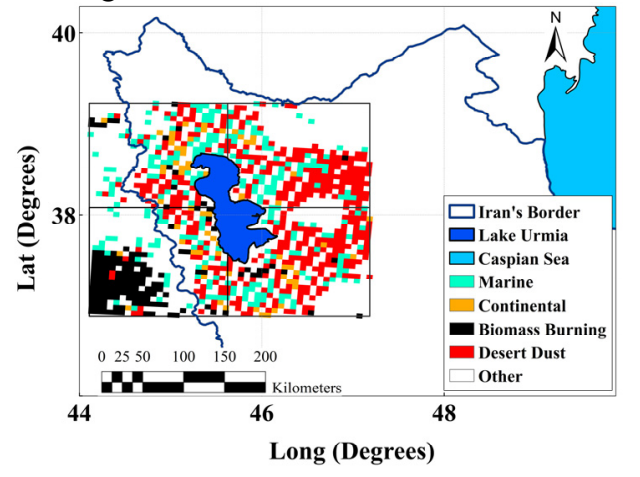

(b)

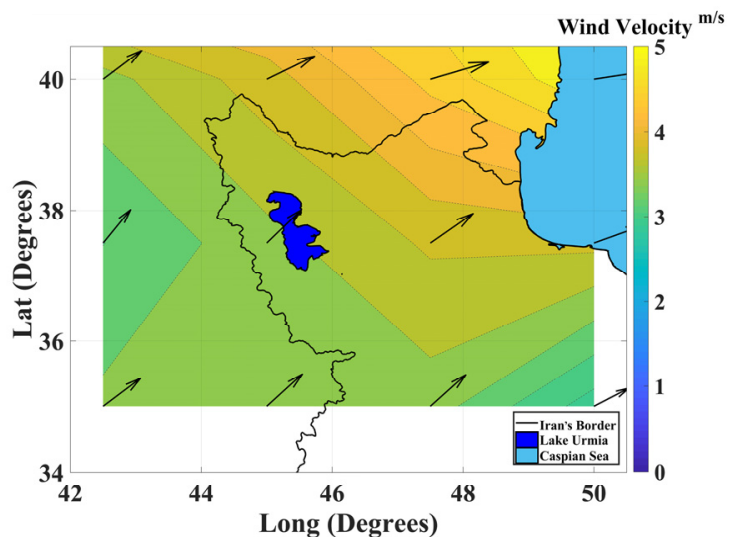

Figure 3. (a) Aerosol types and (b) wind velocity in March 2016.

(a)

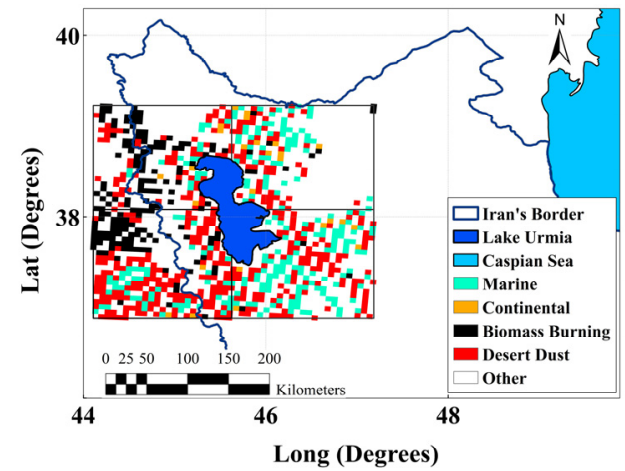

(b)

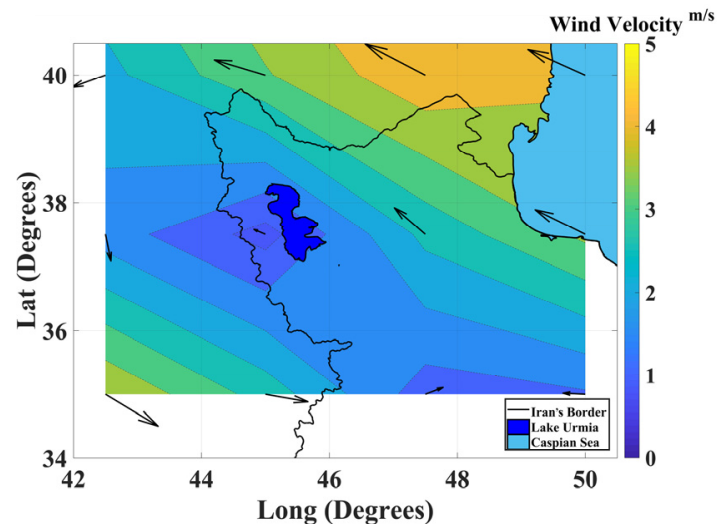

Figure 4. (a) Aerosol types and (b) wind velocity in June 2016.
Based on the classification developed by Toledano et al. (2007), there are four main aerosol types including marine, continental, biomass-burning, and desert dust. As we can see, the dominant aerosol types over the domain are desert dust and marine in March and June 2016. Based on the results, desert dust is dominant particularly over east part of the lake in March. There is biomass-burning aerosol observed in the south-west (SW) of the region in March, which was transferred by the dominant wind to the region. On the other hand, desert dust is mostly significant over southern part of the lake in June and marine aerosol is more dominant over eastern part. The pattern of aerosol types has changed in June. For instance, biomass-burning aerosol in SW in March has moved to the northern part of the subregion in June and instead mostly desert dust and marine aerosol cover the southern part of SW.

A local wind from the Caspian Sea located at the north-east of the study domain influences regional weather. The dominant air mass in the region can be different through the year. Although mostly westerly winds transport dust, marine, and anthropogenic aerosols to the region in March, the easterly winds result in higher concentrations of marine aerosol (e.g. from Caspian Sea) in June (Fig. 4). Westerly winds over the region in March can erode the dry bed of the lake and transport salt and sediments (e.g. see high concentration of dust in east part of the basin in Fig. 3). But it has to be noted again that the large load of the observed marine aerosol type in the eastern part of the domain in June 2016 could also be caused by low aerosol load values at all (almost background values at this month).

Another important type of aerosol (in addition to mineral dust and marine) in the basin is aerosol produced by biomass burning. The sources of this aerosol are wildfires in forests and other ecosystems in the neighbouring countries located in the west of the study area (e.g. Georgia, Turkey, and Iraq). The frequency of forest fires increases with temperature. This aerosol is transported to the study area by the westerly winds. Thus, wind speed and direction are important factors determining types of aerosols.

There are relatively few pixels covered by the continental aerosol in March and June. These sparse pixels may contain a mixture of marine, continental, and urban-polluted aerosols, which can be considered as the background conditions. To reduce uncertainties in this classification a detailed analysis including experimental assessment and continuous measurements is necessary.

\section{Conclusions}

Unsustainable water use in agriculture caused Lake Urmia to dry up. The dramatic desiccation of the Lake Urmia has significantly increased aerosol concentration (particularly desert dust), which has serious health-related consequences. Lake Urmia, which was once a natural habitat of many species including Artemia, fishes, and flamingos, no longer supports these species due to high water salinity. Desiccation of the lake increases salinity of the water and soil, which accelerates soil erosion and desertification. Winds can entrain and transport salt and 
mineral dust, and intensify strong dust storms. Thus, desertification and disappearance of the lake affect weather-related hazards.

This study used satellite data to evaluate different types and sources of the aerosols over Lake Urmia, which has been drying fast. Toledano et al. used threshold values of the AOD and its spectral dependence to identify the aerosol types at a Spanish coastal site. The same threshold values of the AOD and the Ångström exponent were used to classify the particle types over the Lake Urmia basin. This classification can identify the main aerosol types over the region, but is limited to the definition of the threshold values for the different aerosol types. More local measurements are necessary to proof and/or access the threshold values for the Urmia lake region.

The results show that the monthly pattern of the two main aerosol types including desert dust and marine types are different in the region. The sources of these aerosol types can vary in different seasons. Although wind pattern can help to find the sources, more field measurements are required to validate the results. Furthermore, the relevance of the dust events and background conditions in the basin suggested a more complete assessment that needs observations and possibly different threshold values.

This research is sponsored by the Urmia Lake Restoration Program (ULRP). We thank UNESCO Chair in Water and Environment Management for Sustainable Cities in Sharif University of Technology for their help in this research.

\section{References}

1. P. Micklin, Environ. Earth Sci. 75(9), 1-15 (2016)

2. N.M. Mahowald, Geophys. Res. Lett. 30, 30-33 (2003)

3. A. Di, Y. Xue, X. Yang, J. Leys, J. Guang, L. Mei, J. Wang, L. She, Y. Hu, X. He, Y. Che, C. Fan, Remote Sens. 8(9) 702 (2016)

4. N.C. Hsu, S.-C. Tsay, M.D. King, J.R. Herman, IEEE Trans. Geosci. Remote Sens. 42(3), 557-569 (2004)

5. N.C. Hsu, S.-C. Tsay, M.D. King, J.R. Herman, IEEE Trans. Geosci. Remote Sens. 44(11), 3180-3195 (2006)

6. P. Ginoux, D. Garbuzov, N.C. Hsu, J. Geophys. Res. Atmos. 115, D05204 (2010)

7. C. Toledano, V.E. Cachorro, A. Berjon, A.M. De Frutos, M. Sorribas, B.A. De la Morena, P. Goloub, Q. J. R. Meteorol. Soc. 133, 795-807 (2007)

8. A.K. Prasad, R.P. Singh, J. Geophys. Res. 112, D09208 (2007) 